experience know how laborious is the solution of twenty simultaneous equations. Prof. Brown estimates the solution of the equations at half the labour of obtaining them, in addition

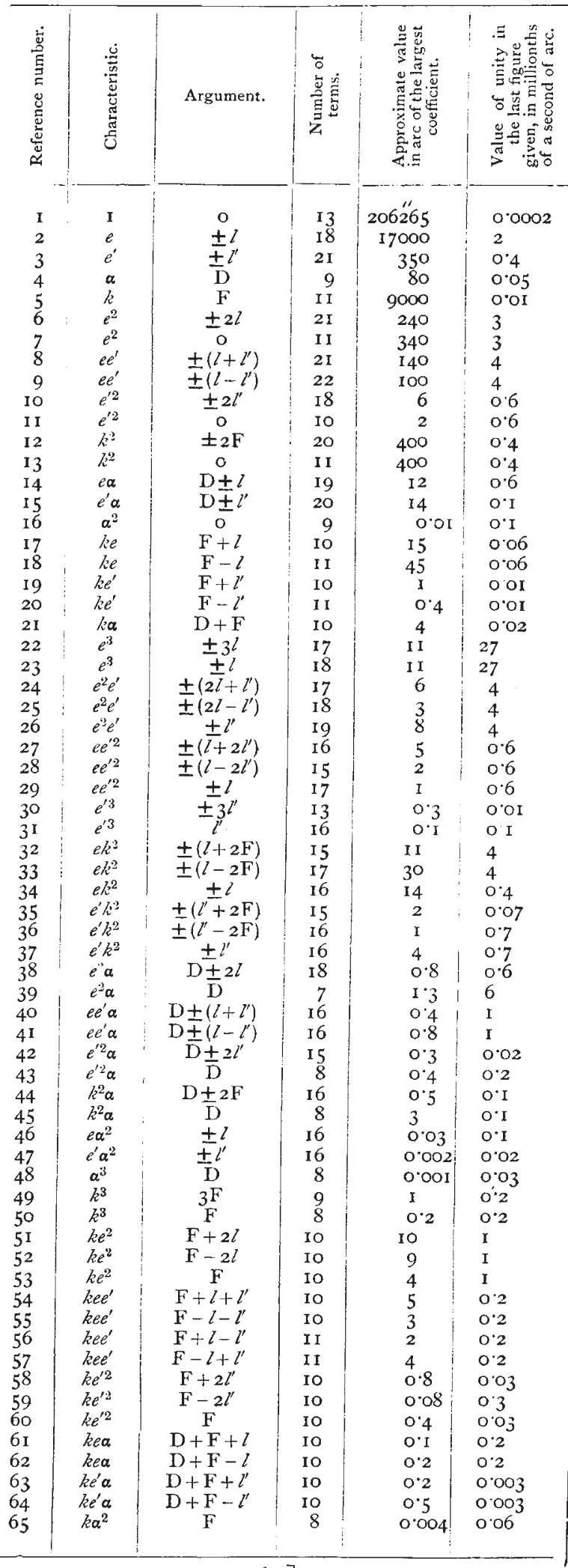

to the fact that this portion of the work is peculiarly liable to numerical error. He may therefore be congratulated on having obtained an algebraical solution, reducing the operation of finding fresh terms to mere multiplication of series. The mathematical investigation is referred to as destined for publication elsewhere, and does not appear in the memoir. The underlying principle is that when in a differential equation of the $n$th order there are $n$ - I integrais known, when the righthand member of the equation is zero, then a particular integral in the general case can be obtained. In the lunar theory the differential equation is, in effect, of the fourth order, and three integrals are known, two representing the elliptic inequality and the third a variation of the epoch.

For forming the right-hand sides of later stages, the quotient of each set of terms by the variation terms is required. As divisions are troublesome, these quotients are the quantities sought in the first instance : the new set of terms can then be obtained by a multiplication. The quotients referred to are given algebraically as the sum of four products, each product being that of two series. It is inconvenient, in the numerical application of the above method, that small coefficients often appear as differences of comparatively large numbers. Dr. Brown gives as an example a case where a coefficient 2 arises as the sum of separate coefficients

$$
-6418+6496+316-392
$$

from the above-mentioned four products.

Terms of long period require a special treatment, but the general methods apply to the other terms of the group. The loss of accuracy is reduced to that due to the first, instead of the second, order of the small divisor.

When the period is that of the elliptic inequality, a new part of the motion of the perigee has to be determined. Calling this new part $c_{\lambda / e}$ a new unknown term $\zeta^{-1}(\mathrm{D}+m) \cdot u_{e} c_{\lambda / e}$ appears, and is transposed to the right-hand side of the equation, so that the quartities $\mathrm{A}$, which in other cases are completely known, now appear in the form $\mathrm{B}+c_{\lambda / e} b$, where $\mathrm{B}, b$ are known. Dr. Brown has already shown in the first part how $c_{\lambda / e}$ may be obtained before the coefficients of the inequalities are calculated. When this has been done, one of the equations becomes redundant. Another is already redundant, until the meaning of the arbitrary constant denoting the ellipticity is defined with further precision. Dr. Brown defines the arbitrary constant so that $\epsilon_{0}-\epsilon_{0}{ }^{\prime}=I$ to all orders; hence $\lambda_{0}=\lambda_{0}{ }^{\prime}$. The other coefficients $\lambda_{l}, \lambda_{l}^{\prime}$ consist of three parts, one proportional to $c_{\lambda \mid e}$, and arising from the quantities $b$, a second arising from the quantities $B$, and a third proportional to $\lambda_{0}$. The two equations for which $\iota=0$ then give a double determination of $\lambda_{0}$, and furnish a check upon the numerical accuracy. Many of the quantities that occur in this arrangement of the computations are of service at subsequent stages.

The treatment of the third coordinate follows the same lines, and only differs in being more simple.

The foregoing table exhibits the extent of the calculations already performed, and the results of the first part are for convenience included in it.

The decrease of accuracy of the terms in the twenty-second and twenty-third groups is due to the period of one term approximating to the synodic period. Even in these cases, the coefficients are given to less than one-thousandth part of the least quantity that could be detected by observation.

P. H. C.

\section{INVESTIGATIONS OF DOUBLE CURRENTS IN THE BOSPHORUS AND ELSEWHERE. 1}

$A \mathrm{~S}$ my books and papers are published chiefly in the Russian language, they are not very well known in this country. A short account of some of my results may therefore not be with. out interest. I cannot, in the course of my address, make you familiar with all my works, and wish at the present moment only to draw your attention to the interesting phenomena of double currents in the Straits of Bosphorus, Gibraltar, Bab-elMandeb, Formosa, and La Pérouse.

The Strait of Bosphorus joins the Black Sea and the Marmora Sea. The Black Sea water has in it-roughly speaking-half the quantity of salt found in the water of the Mediterranean. 1 Abridged from a paper by Vice-Admiral S. Makaroff in the Proceedings of the Royal Society of Edinburgh ( rol. xxii. No. 4, $x 8 c 9$ ). 
The water of the lower strata or the Marmora Sea has the same composition as the water of the Mediterranean. The upper strata, say from ten fathoms upwards, contain water of intermediate salinity between the water of the Mediterranean and the water of the Black Sea. This difference in the salinity of the water is the chief reason of the enormous double current of the Bosphorus. Let us imagine that at a certain given moment the level of both seas is at the same height. The pressure of the column of water in the Marmora Sea will be greater than that in the Black Sea ; the difference would increase with the depth, and it would disappear at the surface. For this reason, the water in the lower strata of the Marmora Sea rushes into the Black Sea, keeping close to the bottom. That rush of water after a certain time will raise the level of the Black Sea, producing a difference in the level of the two seas, which causes a superficial current to flow out of the Black Sea in the opposite direction to the under current. Here we see distinctly that the principal reason for the double current is the difference in the salinity of the water, and should that difference in salinity cease the double current would be discontinued. The fact is that in the Black Sea evaporation does not exceed the quantity of water supplied by rains and streams, and this excess of fresh water maintains the difference of salinity in the waters of the Black Sea and Mediterranean.

The existence of double currents in the Bosphorus was known long ago, and Marsilli in I68I, in his letter to Queen Christina of Sweden, has described them. Later they were somehow forgotten, and some interesting papers have been published, in which the authors try to prove that the double current was legendary. Rear-Admiral Sir W. J. L. Wharton (who is now at the head of the Hydrographic Office) was the first to show by direct observations that a double current existed in the Bosphorus. I was there a few years after him, commanding the stationary steamer Taman. I began to take observations of the specific gravity of the water at different depths, and I found out that the water forming the lower strata contained twice as much salt as the water of the upper strata; after this, a double current was quite evident to me.

I do not wish to detain you with an account of the different results referring to the velocity of both currents, and will only point out to you that the lower current is similar in many details to an ordinary river, while, on the contrary, the upper current differs much from an ordinary river, probably for the reason that, while the surface of it is falling gradually down, the bottom rises constantly.

The difference of level of the Black Sea and Marmora Sea, calculated from the difference in the specific gravity of the water, I found for the month of July I 882 to be I. 396 feet.

In the Strait of Gibraltar I had only five stations, and made my observations one day only. I had no opportunity of measuring the velocity of the current, but the phenomenon is very similar to what I found in the Bosphorus. The water of the Atlantic rushes into the Mediterranean, the difference between the surface levels being, according to my calculations, 0.54 foot.

The evaporation of water from the Mediterranean is greater than the quantity supplied by rivers and rains. For this reason, the water becomes more dense, settles down, and goes back to the Atlantic by the under current.

I wish to point out here that the temperature of the lower strata of the Mediterranean coincides with the mean winter temperature of the air in the eastern part of the sea. This is quite evident, because in winter the temperature of the water to a great depth corresponds to the temperature of the air. In summer, the surface water is much warmer, but this high temperature cannot penetrate to a great depth. I am sorry that I have not time to discuss more fully this question, but in the Straits of Bab-el-Mandeb we have the same phenomena as in the Gibraltar Strait and Mediterranean. Here again-by my observations - the temperature of the lower water strata coincides with the winter temperature of the air at the place where the water settles down.

In the three straits already mentioned we have a double current: superficial and bottom current. In the Straits of Formosa and La Pérouse there are also two currents, but both are superficial.

I ought to mention that the influence of the rotation of the earth on the direction and velocity of the currents cannot be over-estimated. I shall not discuss this question fully, but the fact that in every salt inland sea there is a circular rotation of the water in a direction opposite to the apparent movement of the sun, shows that the rotation of the earth has very much to do with the direction of the currents. In the vicinity of islands, for the same reason, the water follows a direction coinciding with the apparent movement of the sun. It is for this reason also that the water alongside the Chinese coast flows to the south during the north-easterly monsoon as well as during the south-westerly monsoon. The Kuro-Siwo current going to the north and north-east cannot touch the Chinese coast because there is brackish water flowing to the south-west.

In the Strait of Formosa the specific gravity and temperature of the water at the Chinese coast are quite different from what is observed off the coast of Formosa. This difference in the temperature and specific gravity may give to a sailor a good guide for a fair passage through the Strait. The temperature of the water, say, in the month of February at the Chinese coast is $\mathrm{II}^{\circ} \mathrm{C}$., while at the coast of Formosa it is $20^{\circ}$. If the captain will try during the month of February to follow the line of the temperature of $15^{\circ}$ he will pass at a good distance from the dangers of both coasts. Moreover, at the Chinese coast in winter it is possible to find water at less than $10^{\circ} 024^{\circ}$ $\left(\begin{array}{l}\mathrm{S} \\ \mathrm{I} 7 \cdot 5\end{array}\right)$, while at the coast of Formosa it is seldom less than $\mathrm{I} \cdot 0265$.

Every sailor knows how difficult is the passage through the Strait of Formosa. During the north-easterly monsoon the weather is very thick, and the depth of the sea cannot in these places be regarded as giving a good means for determining the position of the ship. It may happen that after a ship leaves, say, Nagasaki the captain never knows his position until he runs on the Chinese coast and wrecks his ship. My opinion is that a regular temperature service should be arranged from Turnabout Lighthouse; everyday a pilot boat should put to sea, taking temperatures both going out and returning, and the tem. perature of the water should be wired to all Chinese and Japanese ports for the information of the captains. By these means many ships would be saved from danger.

The currents in the Strait of La Pérouse are very complicated. There is a very narrow and long strip of cold water, which lies in the direction from N.W. to S.E. ; a vessel crossing that strip in July may have temperatures of $18^{\circ} \mathrm{C}$., then $5^{\circ}$, and again $16^{\circ}$ or $18^{\circ}$. It would take me too long to explain the source from whence the cold water comes, and why it is constantly there ; it is the cause of fogs which render navigation in that place very difficult. I may briefly say that the Kuro-Siwo current partly enters the Sea of Japan, and the excess of water escapes partly through the Strait of La Pérouse into the Okotsk Sea. Due to the rotation of the earth, the current turns to the south-east and flows alongside the Island of Yezo. This water is warm and dense, having much salt in it. The water of the Okotsk Seaparticularly in the vicinity of the Island of Saghalien-is in summer also pretty warm, but it is much lighter than the water of the Kuro-Siwo, and thus while the denser water sinks down, the lighter water tries to rise on the top of it. The difference of level which is produced hereby brings to the surface the cold water of the lower strata.

I studied this Strait in 1887 and 1888 , and published the results of my study, but when I came to the Pacific again in I 895, as the Admiral commanding the squadron, I was very anxious to go to the Strait of La Pérouse to re-investigate the currents, and now I am in possession of very valuable material on this subject, which is almost ready for publication.

I do not propose to take up more of your time at present with particulars of these five straits. I only wish to remind you what important information the thermometer and hydrometer can give in the study of the different parts of our so little-known planet. You know better than I that studies in that direction ought to be continued, and no nation in the world has been so liberal as England, which found means to send out for four years the Challenger with a scientific staff to explore the deep sea. But it is not always possible to find such means, and it is advantageous to associate ordinary seamen with that kind of work.

I should be very glad if oceanographers would come to certain definite opinions with regard to the mode of collecting the information about the temperature of the surface water. It would be a great advantage to knowledge to divide the study of the sea with regard to the temperature. Suppose Russia should take Okotsk Sea, Bering Sea, or Sea of Japan, Black Sea, White Sea, Kara Sea, and the Finnish Gulf, England takes the Atlantic, United States takes Northern Pacific, Germany

NO. I 550 , VOL. 60] 
takes Indian Ocean, France takes South Pacific, Sweden and Norway take North Sea, Baltic Sea and the Arctic Sea. Every nation should extract the information in regard to the temperature from ships' log books, put it in tables of approved description, and send it to the corresponding nation; this will give means to collect enormous information. The observations of every ship in a certain square ought to be placed on a separate card. Boxes containing these cards, say for the North Pacific, would not occupy more space than can be found in a good-sized book-case.

When a new journal of a ship is received, temperatures of sea water observed on board that ship should be placed on the cards, and the cards put in their corresponding place. In this way we should, each year, become richer in the knowledge of the temperature of the surface water, and no observ. ation would be lost. Every observation would increase our knowledge of the temperature of sea water. It would be a real pleasure to see that progress of knowledge, and if ever this system or any other system be accepted, it will help us to study many details which, up to the present time, are unknown.

\section{UNIVERSITY AND EDUCATIONAL INTELLIGENCE.}

MR. R. L. JACK, Government Geologist, Queensland, now on a visit to this country, is to receive the honorary degree of LL.D. of Glasgow University on July 20.

Mr. E. A. Minchin, Fellow of Merton College, Oxford, has been elected to the Jodrell Professorship of Zoology in University College, London, in succession to Prof. W. F. R. Weldon.

THE Bill for establishing a Department of Agriculture and Technical Instruction in Ireland was read for a second time in the House of Commons on Thursday last, and referred to the Standing Committee on Trade.

FOR the purpose of encouraging the study of botany, the London Technical Education Board have had the botanical gardens in Battersea, Ravenscourt and Victoria Parks laid out upon an organised plan. Good collections of plants, representing various natural orders, have been obtained, and suitable arrangements have been made for the convenience of teachers and students. The more important trees and shrubs in the parks have been labelled, and lists have been supplied for insertion in the botanical guide which the Board proposes to issue shortly for the convenience of students. Teachers of botany can obtain tickets for themselves and pupils for admission to the botanical gardens at the Battersea, Ravenscourt and Victoria Parks by application to the Secretary of the Board.

$\mathrm{By}$ the recent gifts of Mrs. Stanford (Science states), Leland Stanford Jr. University becomes the richest university in the world, far surpassing in its resources Harvard, Columbia, or any other university. The resources of the University consist of three great farms, aggregating 95,000 acres of land, deeded by Act of Legislature. On one of these farms, which constitutes the University Campus, buildings to the value of one million dollars were erected before Senator Stanford's death. By his will the University received 2,500,000 dollars in cash, invested in interest-bearing bonds. During the litigation following his death, Mrs. Stanford gave to the University (by deed) her own private fortune, amounting to about a million dollars. By her recent gift she transferred the residue of the estate to the University, it being necessary to do this by deed of gift under the laws of the State. The property just transferred has a commercial value-judging from the revenue stamps put upon the deeds-of $35,000,000$ dollars. What its actual value may be only the uture can determine. The income arising from this final gift is at present relatively small, as by agreement among the railroads, in bonds and stock of which it largely consists, the earnings are for a time to be used in freeing the property from debt and in making improvements.

At the annual dinner of the Old Students' Association of the Central Technical College, held on Thursday last, Prof. W. E. Ayrton, in proposing the toast of the Association, referred to the progress of the College and the insufficiency of accommodation due to the continued increase in the number of students. $\mathrm{He}$ announced that the electrical department would soon be greatly extended by the erection of a large new dynamo room nearly six times the size of that at present in use, and occupy. ing a considerable part of the ground floor of the new building of the Royal School of Art Needlework adjoining the College. The accommodation for this department would be further increased by the completion of a new drawing office and a new lecture theatre. Sir Philip Magnus, in proposing the toast of the College and its professors, remarked that the College was that day entering on a new period in its career, for it was likely to become an integral part of the new University of London, which had decided the day before to move into new quarters at the Imperial Institute next door to the College. The needs of the College were recognised in the new University by the decision to appoint a faculty of engineering for the first time in the history of University education, and by the variation of the University matriculation examination to suit the requirements of different classes of students. Prof. Armstrong, in replying to the toast of the Chairman, alluded to the research work done at the College, especially in relation to its value as a means of mental training.

\section{SCIENTIFIC SERIALS.}

Bulletin of the Amerian Mathematical Society, June.-Prof. F. N. Cole reports the April meeting of the Society held in New York City, and summarises the thirteen papers which were contributed. He also indicates where the papers themselves may be or will be found. - Surfaces of revolution in the theory of Lamé's products is a paper which was read by Dr. Safford at the February meeting. It is a review of an article by Haentzschel (reduction der Potentialgleichung), in which that writer criticises results obtained by Wangerin in the Berliner Monats berichte (February 1878 ). Dr. Safford agrees with Wangerin in the results he gets, and so, in his opinion, invalidates Haentzschel's criticisms. - The next article is an enthusiastic review by Mr. Arthur Berry of Picard's "Théorie des Fonctions Algébriques de deux Variables indépendantes."-Another review is one of Jules Tannery's "Leçons d'Arithmétique théorique et pratique," by Prof. J. Pierpont. This latter is pronounced to be the first work on arithmetic which the reviewer has seen which, while intended entirely for secondary instruction, is written in accordance with the new ideas regarding the number concept and the need of rigour. Thus it is a pioneer of a revolution in secondary instruction. -Dr. L: E. Dickson contributes a note on Page's ordinary differential equations ( $c f$. a review of this by Prof. Lovett in the Bulletin, April 1898). The usual notes and new publications close the number.

In the Tournal of the Royal Microsiopical Society for June, besides the usual summary of current researches in zoology, botany, and microscopy, is a further instalment of Mr. F. W Millett's report of the recent Foraminifera of the Malay Archipelago; and an article by the president, Mr. E. M. Nelson, on the rackwork coarse adjustment, in which he traces the history of the application of rackwork to the focussing of the microscope from the time of Bonannus in 1691 down to the most recent improvements.

THE Journal of Botany for July contains an article, with illustrations, on a new British fresh-water alga, by Dr. A. B. Rendle and Mr. W. West, jun. The alga is a new species of the interesting genus Pithophora, first found by Wittrock in a tank in Kew Gardens. Like Wittrock's species, however, it has no claim to the title of "British" beyond the fact that it was found in a canal near Manchester, where it had unquestionably been introduced with cotton-bales. The remaining papers in both the June and the July numbers appeal to those interested in descriptive and geographical botany.

\section{SOCIETIES AND ACADEMIES. \\ PARIS.}

Academy of Sciences, July 3.-M. van Tieghem in the chair.-Considerations on the physical constitution of the moon, by MM. Lœwy and Puiseux. A summary of conclusions arrived at from recent photographic study of the moon. Certain NO. I 550, VOL. 60] 